March - 2010

\title{
Profiles in Self-Regulated Learning in the Online Learning Environment
}

\author{
Lucy Barnard-Brak \\ Baylor University, USA \\ William Y. Lan and Valerie Osland Paton \\ Texas Tech University, USA
}

\begin{abstract}
Individuals who are self-regulated in their learning appear to achieve more positive academic outcomes than individuals who do not exhibit self-regulated learning behaviors. We suggest that distinct profiles of self-regulated learning behaviors exist across learners. In turn, these profiles appear to be associated with significantly different academic outcomes. The purpose of the current study was to examine whether profiles for self-regulated learning skills and strategies exist among learners. To achieve this purpose, we conducted two studies using two different samples. We administered the Online Self-Regulated Learning Questionnaire (OLSQ), a 24-item scale with a 5-point Likert-type response format, to students enrolled in online degree programs at a large, public university located in the Southwestern United States. The OSLQ consists of six subscale constructs, including environment structuring, goal setting, time management, help seeking, task strategies, and self-evaluation. Latent class analyses were performed with participant subscale scores from the OSLQ.

Our results indicate the presence of five, distinct profiles of self-regulated learning replicated across both study samples: super self-regulators, competent self-regulators, forethought-endorsing self-regulators, performance/reflection self-regulators, and non- or minimal self-regulators. Results also indicate that individuals differ significantly in their academic achievement according to their profile membership; for example, minimal and disorganized profiles of self-regulated learning are both associated with similar, poorer academic outcomes (e.g., lower GPAs). These profiles in self-regulated learning may be viewed as contributing to the development of theory by elucidating how exactly individuals are and are not self-regulated in their learning. The authors suggest future research directions.
\end{abstract}

Keywords: Self-regulated learning; online learning 


\section{Self-Regulated Learning}

Self-regulated learning refers to those active and volitional behaviors on the part of individuals to achieve in their learning. These behaviors include but are not limited to goal setting, time management, task strategies, environment structuring, and help-seeking. As skills and strategies that individuals perform, these self-regulated learning behaviors are a function of an individual's desire to achieve in their learning. These skills and strategies of self-regulation have been proffered as being utilized in social relationships as well as in learning (Boekaerts \& Cascallar, 2006). Thus, self-regulated learning is both a function of the skill and the will on the part of individuals (Woolfolk, Winne, \& Perry, 2000). In view of this conceptualization, "self-regulated learning is seen as a mechanism to help explain achievement differences among students and as a means to improve achievement" (Schunk, 2005, p. 85). Self-regulated learning skills and strategies appear to have a dual purpose in both differentiating among individuals with respect to academic achievement while also enhancing academic achievement outcomes.

Self-regulated learning is based upon the assumption that individuals can act as causal agents in their own lives. Self-regulated learning would appear to center on the self as an agent who acts upon his or her environment: "agency is the capability of individual human beings to make choices and to act on these choices in ways that make a difference in their lives" (Martin, 2004, p. 135). However, agency is not only the capability of the individual to act upon the environment but also a requirement for the individual to achieve academically. This agentic perspective provides that individuals who become self-regulated in their learning can act both autonomously and causally to influence their outcomes and experiences. From this broad agentic perspective, the self-regulation of learning can be viewed from a variety of theoretical frameworks that support a self-deterministic perspective. For the purposes of the current study, self-regulated learning will be viewed from a social cognitive theoretical framework.

From a social cognitive perspective, the development of self-regulated learning skills and strategies is a function of the bidirectional interaction of personal, behavioral, and environmental factors, which takes the form of triadic reciprocal causation (Bandura, 1986, 1997; Schunk, 2001; Zimmerman, 1994). Given the bidirectional interaction of factors, the process of developing selfregulated learning skills and strategies appears to be cyclical (Schunk, 2001). The cyclical process in which self-regulated learning skills and strategies develop appears to be a function of personal, behavioral, and environmental factors adjusting, modifying, and changing as they interact with one another in each cycle or iteration. In a student's learning process, these factors interact with each other in each cycle, which changes the student's self-regulated learning skills and strategies (Bandura, 1986, 1997).We suggest that iterative may be a better way of describing the process in which self-regulated learning skills and strategies develop.

The term cyclical implies that individuals must be involved in a prescribed cycle of personal, behavioral, and environmental events before self-regulated learning skills and strategies may develop. We suggest that individuals can also adjust, modify, or change their self-regulated learning skills and strategies by the interaction of two of these factors, such as personal and behavioral factors or personal and environmental factors alone. For instance, an individual can 
engage in the classic study technique of cramming the night before a test. The individual wakes up very tired for his/her examination. Without environmental feedback (e.g., a test score), the individual may then decide that the behavior of cramming is non-advantageous. Some individuals, however, may require their environment to reinforce that this behavior of cramming is non-advantageous. As the development of self-regulated learning skills and strategies can be considered to be a dynamic process, where some skills and strategies develop before others (Pintrich, 2000), the term iterative may depict this process better.

In theorizing about the development of self-regulated learning skills and strategies, Zimmerman (1998) proposed a three-phase model. The first phase, forethought, refers to the skilled and strategic processes that precede and set the stage for performance in learning. These processes would include but are not limited to goal-setting, attribution, self-efficacy of eminent tasks, and the intrinsic motivation to perform the learning task. This forethought phase may be thought of as consisting of those self-regulated learning skills and strategies that are at the intersection of the cognitive and motivational factors that typically occur prior to or as the student enters the learning process. Self-regulated learning skills and strategies such as environment structuring and goal setting may be associated with the forethought phase.

The second phase, the performance control or volitional phase, consists of the skilled and strategic processes that occur during the learning process. These skilled and strategic processes include but are not limited to attention, affect, and monitoring of action. Self-regulated learning skills and strategies, such as time management, task strategies, and help seeking, are associated with the performance control phase. In the third and final phase, the self-reflection phase, individuals react and respond to their self-regulated efforts in the learning process by evaluating the outcomes of their performance. During the final self-reflection phase, the individual will selfevaluate based upon social comparisons and adjust the implementation of skills and strategies in the forethought and performance control phases for the next learning task. Self-regulated learning skills and strategies such as self-evaluation may be associated with the self-reflection phase.

The purpose of the current study was to examine whether profiles or types of self-regulated learning skills and strategies exist. No research has yet to examine the presence of profiles in selfregulated learning skills and strategies except to acknowledge that there are differences according to the self-regulated learning skills and strategies characterized by students (Greene \& Azevedo, 2007). While acknowledging that student characteristics do play a part in self-regulated learning skills and strategies, Greene and Azevedo (2007) have noted the lack of clarity as to how we can account for these differences. We suggest that the demarcations of theory presenting the development of self-regulated learning as a cyclical or iterative process may have limited the mindscape of researchers, preventing them from considering profiles or types of self-regulation among learners as they develop these self-regulated learning skills and strategies. To achieve the purpose of the current study, we conducted two studies using two different samples in the online learning environment. Examining self-regulated learning skills and strategies in the online learning environment is especially important given that this environment has been noted as requiring individuals to be more autonomous in their learning, the prerequisite of which is being able to self-regulate (Ally, 2004). We employed latent class analysis techniques to discern 
whether any such profiles for self-regulated learning skills and strategies existed. We conducted our analyses across two study samples to cross-validate our findings with regard to any profiles for self-regulated learning discerned. In the second study, we examined additionally the association of an individual exhibiting a certain self-regulated learning profile (as discerned by latent class membership) with academic achievement as measured by grade point average (GPA). The method and results of each study according to each sample are reported consecutively.

\section{Study One}

\section{Participants}

Study 1 consisted of students enrolled in online degree programs at a large, public university located in the Southwestern United States. Of the students taking online courses, 279 self-selected to complete the survey online by responding to a recruitment e-mail message. Approximately $42 \%$ of the participants identified themselves as male $(n=117)$ while $58 \%$ identified themselves as female $(n=162)$. With regard to ethnicity, approximately $76 \%$ of the participants identified themselves as white $(n=212)$ while approximately $14 \%$ identified themselves as Hispanic $(n=$ $39), 6 \%$ as Asian American $(n=17)$, and $4 \%$ as African American $(n=11)$. The student gender distribution (117 males vs. 162 females) in this study may be considered representative of those enrolling in distance education courses across the nation (Kamarae, 2001). The student ethnic/racial distribution in this study was representative of the student population of the university studied. With values for age ranging from 20 to 65 years old, the mean age of participants was 34 with a standard deviation of 9.10. A total of 19 different academic degree programs and a total of 134 different U.S. postal zip codes were represented. The average number of courses taken at a distance was 9.52 with a standard deviation of 8.64.

\section{Measures}

The Online Self-Regulated Learning Questionnaire (OSLQ; Barnard, Lan, \& Paton, 2008; Barnard, Lan, To, Paton, \& Lai, 2009) is a 24-item scale with a 5-point Likert-type response format having values ranging from strongly agree (5) to strongly disagree (1). As self-regulated learning skills and strategies appear to be "highly context dependent" (Schunk, 2001, p. 125), the development of an instrument contextualized to the online and distributed learning environments is requisite. Thus, the current study examines self-regulated learning skills and strategies in view of the online learning environment. Though research has indicated that self-reported measures of self-regulation have been unreliable as over-estimates of self-regulated learning (Winne \& Jamieson-Noel, 2002), the OSLQ has revealed satisfactory psychometric properties being validated across two samples of learners in the online and blended learning environments respectively (Barnard, Lan, To, Paton, \& Lai, 2009), despite this bias being reported. As such, data obtained from the OSLQ has also revealed acceptable psychometric properties and statistical significance when examined in relation to epistemological beliefs and academic achievement (Barnard, Lan, Crooks, \& Paton, 2008) and across time (Barnard-Brak, Lan, \& Paton, in press). Additionally, self-regulated learning skills and strategies appear to be associated with perceptions 
of online course communications and collaboration (Barnard, Paton, \& Rose, 2007), and this relationship has been examined with data obtained from the OSLQ, which revealed again acceptable and consistent psychometric properties and statistical significance (Barnard, Paton, \& Lan, 2008).

The OSLQ consists of six subscale constructs, including environment structuring, goal setting, time management, help seeking, task strategies, and self-evaluation. The scores obtained from the measure demonstrated adequate internal consistency of scores with $\alpha=.90$. Nunnally (1978) has suggested that score reliability of .70 or better is acceptable when used in basic social science research, such as in this study. When examining the internal consistency of scores by subscale, values for Cronbach alpha ranged from .85 to .92 , revealing sufficient score reliability on the subscale level. Table 1 contains internal consistencies for scores obtained from each of the subscales (See the appendix for a complete copy of the instrument, including subscale construct designation.)

Table 1

Study One Internal Consistencies for each Subscale

\begin{tabular}{ll}
\hline Subscale & $\alpha$ \\
\hline Environment structuring & .92 \\
Goal setting & .88 \\
Time management & .91 \\
Help seeking & .92 \\
Task strategies & .85 \\
Self-evaluation & .89 \\
\hline
\end{tabular}

\section{Procedure}

The OSLQ was administered online to a sampling frame of 516 students, indicating an approximately $54 \%$ response rate. After data were collected, some items were recoded and reversed per instrument instructions. No modifications were made to the instrument. All participants were assured that their responses would remain anonymous and confidential. Data were imported from the Web into MS Excel format and then imported into SPSS (v. 16.0). Data analyses were performed in MPlus (v. 5.20; Muthén \& Muthén, 2008) and SPSS (v. 16.0). Values for missing data were handled using multiple imputation techniques (e.g., Bayesian estimation). These multiple imputation techniques were employed upon the analysis recommendations of Widaman (2006) when facing a complex model with many parameters to be estimated, such as in the current study.

\section{Analyses}

Latent class analyses were performed with participant subscale scores from the OSLQ. Latent class analyses may be considered a structural equation modeling approach to estimating 
unobserved heterogeneity via categorical latent variables (Muthén, 2002). In contrast to factor analyses and multiple regression techniques, latent class analyses may be considered a personcentered over a variable-centered approach (Muthén \& Muthén, 2000). Thus, person-centered approaches may be considered as answering different research questions by identifying how persons may be classified according to a set of variables (e.g., cluster analyses, discriminant function analyses, and latent class analyses). In contrast, variable-centered approaches may be considered as identifying how variables may be related according to a sample or sub-sample of persons (e.g. factor analyses \& multiple regression techniques). As the purpose of the current study was to identify how persons may possibly belong to certain profiles of self-regulated learning, a person-centered approach may be considered more applicable to our purpose. The greater suitability of the latent class analyses does not imply that other methods and techniques are inferior but rather reflects different research questions.

Four statistics reflecting fit were assessed: Bayesian Information Criterion (BIC); Akaike Information Criterion (AIC); entropy; and the Lo-Mendel-Rubin Likelihood Ratio Test (LMRLRT). BIC is a measure of goodness of fit that penalizes for model complexity (D'Unger, Land, McCall, \& Nagin, 1998; Nagin, 2005). Smaller values of BIC are indicative of better fit. BIC has been viewed as a conservative measure of fit compared to the AIC. Values of AIC may be interpreted in a similar manner to that of BIC, where smaller values indicate better fit. In making model comparisons, differences in BIC (and AIC) of 10 or more were considered to be very strong evidence of model fit corresponding to the odds of 150:1 (Raftery, 1995, p. 115). Entropy values indicate the degree to which classes may be considered distinguishable from one another with standardized values ranging from 0 to 1 (Muthén, 2000). An entropy value closer to 1 indicates the presence of clear, distinct classes and greater power to predict class membership (Muthén \& Muthén, 2001). The LMR-LRT is a test of statistical significance, where the null hypothesis is the number of classes, $c$, estimated minus one (e.g., $\mathrm{H}_{0}: c-1$ model fits) (Lo, Mendel, \& Rubin, 2001). For instance, in testing a three-class solution (e.g. $c=3$ ), we would reject or fail to reject a two-class solution (e.g., $c-1=3-1=2$ ) using the LMR-LRT statistic. Additionally, the number of free parameters was also reported for each $c$-class model estimated.

\section{Results}

In performing our latent class analysis, our results indicate support for a five-class solution as compared to the other $c$-class solutions estimated. Of the models tested, the five-class solution model contained the lowest estimated values of BIC $(=1,256.773)$ and $\mathrm{AIC}(=1,156.339)$ and the highest entropy value $(=.85)$, indicating the best model for the data. In evaluating the LMR-LRT statistic, results indicate that the one- through four-class solutions may be rejected, $p<.01$, while we failed to reject a five-class solution, $p=.30$. Table 2 contains the number of free parameters along with values for BIC, AIC, entropy, and the LMR-LRT statistic for each latent class solution tested. Values for the best-fitting five-class solution are also in bold in Table 2. 
Table 2

Study One Summary Statistics for Model Fit of Latent Class Solutions

\begin{tabular}{llllll}
\hline $\begin{array}{llll}\text { Classes } \\
\end{array}$ & $\begin{array}{l}\text { \# of free } \\
\text { parameters }\end{array}$ & BIC & AIC & Entropy & $\begin{array}{l}\text { LMR-LRT } \\
\left(\mathrm{H}_{0}: c-1 \text { model fits }\right)\end{array}$ \\
\hline 1 & 12 & $1,346.459$ & $1,316.329$ & $N A$ & $N A$ \\
2 & 19 & $1,294.699$ & $1,246.992$ & 0.76 & Reject 1-class solution, $p<.01$ \\
3 & 26 & $1,283.172$ & $1,217.890$ & 0.80 & Reject 2-class solution, $p<.01$ \\
4 & 33 & $1,275.567$ & $1,172.708$ & 0.82 & Reject 3-class solution, $p<.01$ \\
$\mathbf{5}$ & $\mathbf{4 0}$ & $\mathbf{1 , 2 5 6 . 7 7 3}$ & $\mathbf{1 , 1 5 6 . 3 3 9}$ & $\mathbf{0 . 8 5}$ & Reject 4-class solution, $\boldsymbol{p}<. \mathbf{0 1}$ \\
& & & & \\
6 & 47 & $1,264.836$ & $1,163.826$ & 0.83 & Do not reject 5-class solution, $p=.30$ \\
7 & & & & \\
\hline
\end{tabular}

In examining our five-class solution, approximately $22 \%(n=61)$ of the sample was estimated to belong to the first class of the five classes or profiles of self-regulation revealed. For the purposes of the current study, we refer to this first class or profile as class 1 and all other classes respectively. Approximately 16\% $(n=46)$ was estimated to belong to the second class (e.g., class $2) ; 12 \%(n=33)$ was estimated to belong to the third class (e.g., class 3$) ; 9 \%(n=25)$ was estimated to belong to the fourth class (e.g., class 4$)$; and the remaining $41 \%(n=114)$ was estimated to belong to the fifth and final class (e.g., class 5). As a result of our latent class analyses, all classes were significantly different from one another in terms of standardized mean subscale scores. Figure 1 displays the standardized means for each subscale according to class. 


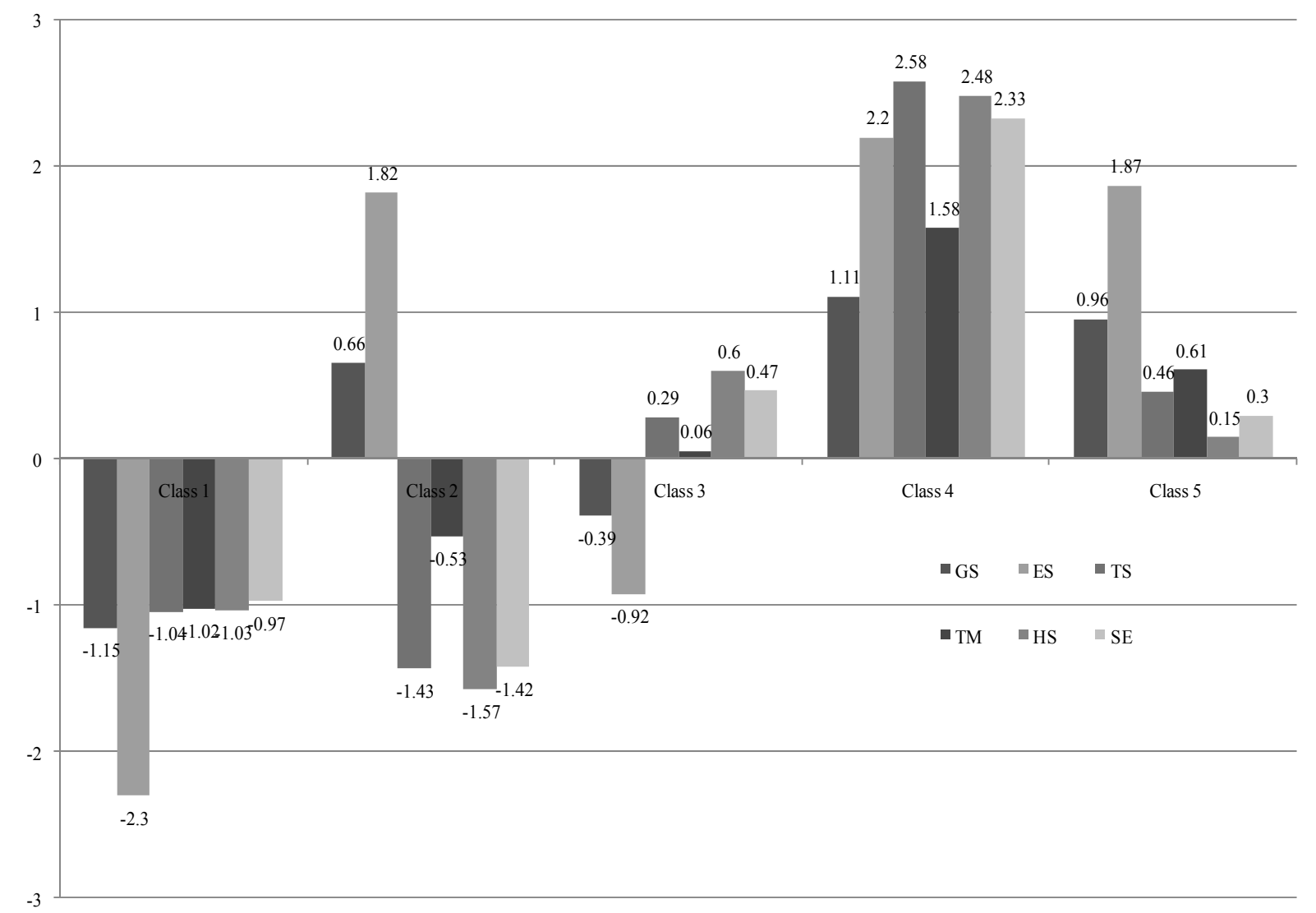

Figure 1. Study 1 standardized subscale means by class.

\section{Study Two}

\section{Participants}

Study 2 consisted of students enrolled in online degree programs at a large, public university located in the Southwestern United States. Of the students taking online courses, 197 self-selected to complete the survey online by responding to a recruitment e-mail message. Approximately $43 \%$ of the participants identified themselves as male $(n=84)$ while approximately $57 \%(n=$ 113) identified themselves as female. With regard to ethnicity, approximately $78 \%$ of the participants identified themselves as white $(n=154)$ while approximately $12 \%$ identified themselves as Hispanic $(n=23), 7 \%$ as Asian American $(n=12)$, and $3 \%$ as African American ( $n$ $=8$ ). The student gender distribution (84 males vs. 113 females) in this study may be considered representative of those enrolling in distance education courses across the nation (Kamarae, 2001). The student ethnic/racial distribution in this study was representative of the student population of the university studied. With values for age ranging from 22 to 65 years old, the mean age of participants was 38 with a standard deviation of 9.93. A total of 22 different academic degree programs and a total of 136 different U.S. postal zip codes were represented, which is similar to that of the study 1 sample. The average number of courses taken at a distance was statistically similar to that of participants in study 1 with a mean of 10.21 and a standard deviation of 8.70 . In 
contrast to study 1, data for GPA was also collected, which revealed a mean of 3.53 and a standard deviation of .41 .

\section{Measures}

The same measure employed in study 1 was utilized in study 2 . For study 2 , the scores obtained from the measure demonstrated an adequate internal consistency of scores with $\alpha=.92$. When examining the internal consistency of scores by subscale, values for Cronbach alpha ranged from .88 to .95 , revealing sufficient score reliability on the subscale level. Table 3 contains the internal consistencies for scores obtained for each subscale.

Table 3

Study 2 Internal Consistencies for each Subscale

\begin{tabular}{ll}
\hline Subscale & $\alpha$ \\
\hline Environment structuring & .92 \\
Goal setting & .95 \\
Time management & .89 \\
Help seeking & .88 \\
Task strategies & .92 \\
Self-evaluation & .94 \\
\hline
\end{tabular}

\section{Procedure}

Study 2 consisted of the same procedure as study 1 . The OSLQ was administered to a sampling frame of 434 students, indicating an approximately $45.4 \%$ response rate.

\section{Analyses}

Study 2 consisted of the same procedures as study 1 with regard to latent class analysis techniques. Additionally, however, we analyzed how latent class or profile of self-regulated learning membership was associated with GPA by performing a one-way univariate analysis of variance (ANOVA) with GPA as our dependent variable. This GPA data is the actual cumulative grade point average of students retrieved from the university with the consent of the participant. After conducting our omnibus ANOVA, we then conducted post hoc tests. Cohen's $d$ was calculated as the measure of effect size. Cohen's $d$ values of $.20, .50$, and .80 or larger indicate small, medium, and large effect sizes respectively (Cohen, 1988).

\section{Results}

In performing our latent class analysis, our results indicate support for a five-class solution as compared to the other $c$-class solutions estimated. Of the models tested, the five-class solution 
model contained the lowest estimated values of BIC $(=2,580.964)$ and AIC $(=2,455.064)$ and the highest entropy value $(=.89)$, indicating the best model for the data. In evaluating the LMR-LRT statistic, results indicate that the one- through four-class solutions may be rejected, $p<.001$, while we failed to reject a five-class solution, $p=0.17$. Table 4 contains the number of free parameters along with values for BIC, AIC, entropy, and the LMR-LRT statistic for each latent class solution tested. Values for the best-fitting five-class solution are also in bold on Table 4.

Table 4

Study 2 Summary Statistics for Model Fit of Latent Class Solutions

\begin{tabular}{llllll}
\hline Classes & $\begin{array}{l}\text { \# of free } \\
\text { parameters }\end{array}$ & BIC & AIC & Entropy & $\begin{array}{l}\text { LMR-LRT } \\
\left(\mathrm{H}_{0}: c-1 \text { model fits }\right)\end{array}$ \\
\hline 1 & 12 & $2,910.656$ & $2,872.886$ & $N A$ & NA \\
2 & 19 & $2,659.007$ & $2,599.204$ & 0.74 & Reject 1-class solution, $p<.01$ \\
3 & 26 & $2,615.781$ & $2,533.946$ & 0.79 & Reject 2-class solution, $p<.01$ \\
4 & 33 & $2,591.909$ & $2,480.042$ & 0.82 & Reject 3-class solution, $p<.01$ \\
$\mathbf{5}$ & $\mathbf{4 0}$ & $\mathbf{2 , 5 8 0 . 9 6 4}$ & $\mathbf{2 , 4 5 5 . 0 6 4}$ & $\mathbf{0 . 8 9}$ & Reject 4-class solution, $\boldsymbol{p}<.01$ \\
6 & 47 & $2,593.235$ & $2,581.052$ & 0.86 & Do not reject 5-class solution, $p=.17$ \\
7 & & & & \\
\hline
\end{tabular}

In examining our five-class solution, approximately $19 \%(n=38)$ of the sample was estimated to belong to the first class of the five classes or profiles of self-regulation revealed. For the purposes of the current study, we refer to this first class or profile as class 1 and all other classes respectively. Approximately $15 \%(n=31)$ was estimated to belong to the second class (e.g., class 2), $6 \%(n=12)$ was estimated to belong to the third class (e.g., class 3$), 20 \%(n=39)$ was estimated to belong to the fourth class (e.g., class 4$)$, and the remaining $39 \%(n=77)$ was estimated to belong to the fifth and final class (e.g., class 5). As a result of our latent class analyses, all classes were significantly different from one another in terms of standardized mean subscale scores. Figure 2 displays the standardized means for each subscale according to class. 


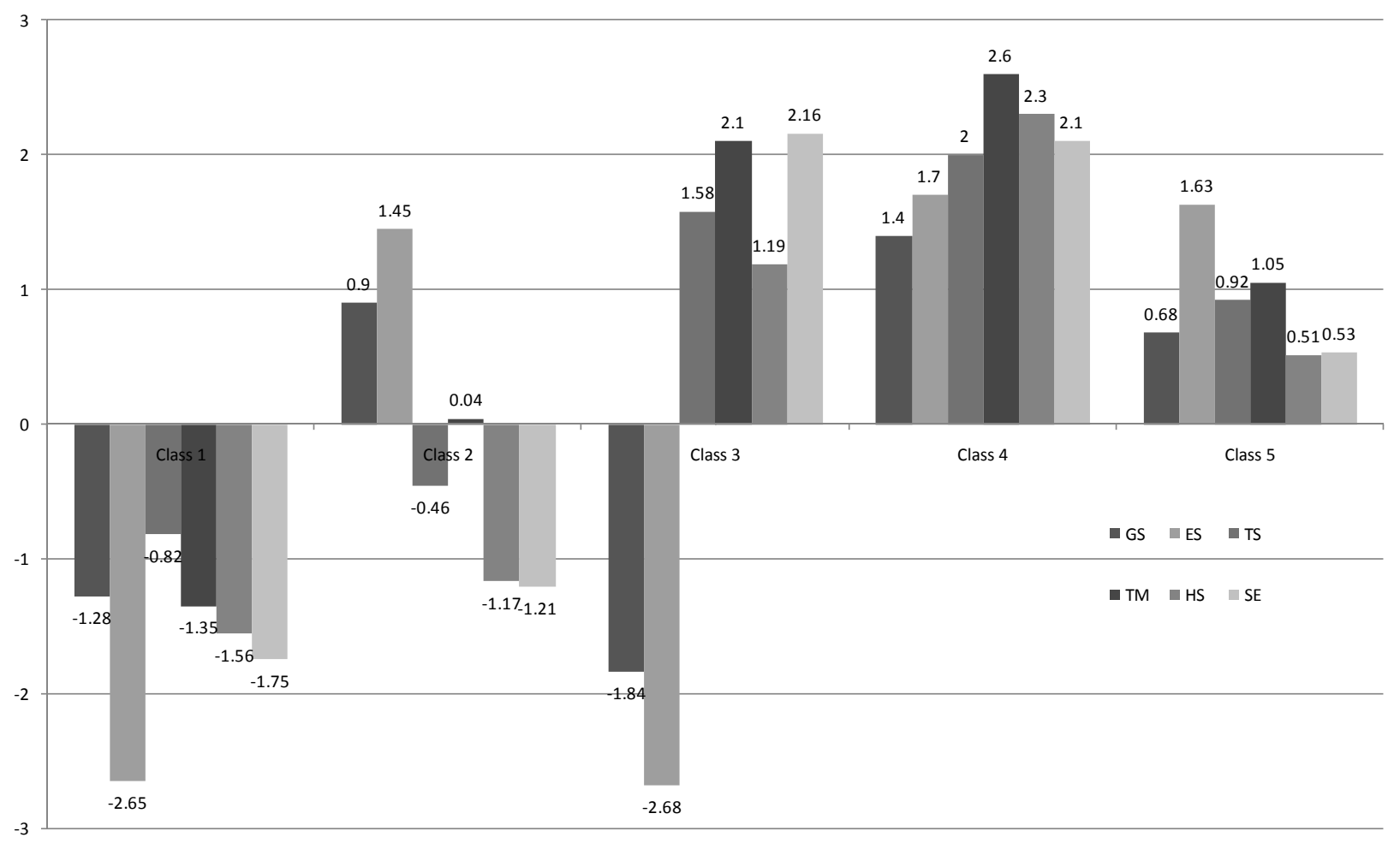

Figure 2. Study 2 standardized subscale means by class.

As we collected GPA data in Study 2, we next examined whether there were any significant differences in academic achievement according to class or profile membership. Results indicated that participants differed significantly in their GPA according to their class or profile of selfregulated learning membership, $F(4,196)=15.69, p<.01, f=.65$. As a measure of effect size, Cohen's $f$ values of $.10, .25$, and .40 or larger indicate small, medium, and large effect sizes respectively (Cohen, 1988). Thus, a Cohen's $f$ value of .65 indicates a large effect suggesting overall substantial differences in GPA according to class or profile of self-regulated learning membership. Table 5 contains the means and standard deviations for GPA according to each class.

Table 5

Descriptive Statistics according to Class

\begin{tabular}{ll}
\hline Class & $M \& S D$ \\
\hline Class 1 & $M=3.37, S D=.63$ \\
Class 2 & $M=3.58, S D=.34$ \\
Class 3 & $M=3.55, S D=.38$ \\
Class 4 & $M=3.91, S D=.20$ \\
Class 5 & $M=3.91, S D=.18$ \\
\hline
\end{tabular}


After conducting our omnibus ANOVA, we proceeded to conduct post hoc tests. As the assumption of the homogeneity of variances was not met, Levene's $F(4,196)=19.16, p<.05$, we conducted post hoc tests using the Games-Howell procedure (Field, 2005; Kirk, 1995). These post hoc test results indicate that differences among individuals belonging to classes 1,2 , and 3 were statistically non-significant as with differences between individuals belonging to classes 4 and 5. Individuals belonging to classes 4 and 5 revealed significantly higher academic achievement than individuals belonging to classes 1,2 , and 3 with values of Cohen's $d$ ranging from -1.16 to 1.21 for these statistically significant differences. Table 6 contains a summary of these post hoc test results including values of Cohen's $d$ for all significant contrasts.

Table 6

Summary for Significant Post Hoc Tests

\begin{tabular}{lll}
\hline Contrast & Significance & Cohen's $d$ \\
\hline Class 1 vs. class 4 & $p<.001$ & $d=-1.15$ \\
Class 1 vs. class 5 & $p<.001$ & $d=-1.16$ \\
Class 2 vs. class 4 & $p<.001$ & $d=-1.18$ \\
Class 2 vs. class 5 & $p<.001$ & $d=-1.21$ \\
Class 3 vs. class 4 & $p=.03$ & $d=-1.19$ \\
Class 3 vs. class 5 & $p=.04$ & $d=-1.21$ \\
\hline
\end{tabular}

\section{Discussion}

In the current study, we examined whether profiles of self-regulated learning skills exist, which revealed the presence of five classes or profiles of self-regulated learning strategies or skills invoked by individuals across two samples. In both study 1 and study 2, individuals belonging to the first class or profile of self-regulated learning skills endorsed the skills and associated with self-regulated learning the least. In study 1 , approximately $22 \%$ of the sample belonged to this least self-regulated learning class while approximately $19 \%$ of the sample in study 2 belonged to this class. We term this class as depicting the profile of individuals who are non-self-regulators or minimal self-regulators in their learning. At the other end of the spectrum, individuals belonging to the fourth class appeared to be composed of super self-regulators as endorsing the skills and strategies of self-regulated learning highly across all subscales. In both study 1 and study 2 respectively, $20 \%$ and $9 \%$ belonged to the class that depicts the profile of individuals who are highly self-regulated in their learning.

Individuals belonging to class 5 appeared to be moderately to highly endorsing skills and strategies of self-regulated learning but not to the same extent as those individuals who may be considered super self-regulators. We consider individuals belonging to this class as exhibiting the profile of competent self-regulators. We hypothesize that these competent self-regulators 'do what it takes' in terms of invoking self-regulated learning strategies and skills to achieve well in their learning but they don't do much more. In study 1, approximately $39 \%$ of the sample belonged to the class that profiles competent self-regulators while approximately $41 \%$ of the 
sample in study 2 belonged to this class. Competent self-regulators appear to be the largest class of self-regulators with the highest percent in each sample belonging to class 5 depicting this profile.

The remaining two classes (e.g., classes 2 and 3) were more difficult profiles of self-regulated learning to interpret. Individuals belonging to class 2 appeared to more highly endorse goal setting and environment structuring as self-regulated learning strategies and skills while endorsing task strategies, time management, help seeking, and self-evaluation to much lesser extents. As goal setting and environment structuring typically occur in the forethought phase of the development of self-regulated learning skills and strategies (Zimmerman, 1998; Zimmerman \& Schunk, 2001), we suggest that these learners may be best described as belonging to a profile of forethought-endorsing self-regulators. We consider individuals belonging to this profile of selfregulated learning skills and strategies to be concerned with self-regulation in the a priori or proactive sense, but they are not necessarily concerned with following through with the use of task strategies, time management, help seeking, or self-evaluation in their learning. Approximately $16 \%$ and $15 \%$ appeared to belong to this class depicting this profile of forethought-endorsing self-regulated learning in study 1 and study 2 respectively.

Individuals belonging to class 3 appeared to more highly endorse task strategies, time management, help seeking, and self-evaluation as self-regulated learning skills and strategies compared to goal setting and environment structuring. As task strategies, time management, help seeking, and self-evaluation are behaviors more typically associated with the performance control and self-reflection phases in the development of self-regulated learning strategies and skills, we suggest that these learners may be best described as belonging to a profile of performance control or self-reflection-endorsing self-regulators. As self-regulated learning skills and strategies pertaining to both the performance control and self-reflection phases were highly endorsed in this class, we will term individuals belonging to class 3 as performance/reflection-endorsing selfregulators. We consider individuals belonging to this profile of performance/reflection-endorsing self-regulators as being more concerned with self-regulation in the post hoc or reactive sense; they are not necessarily concerned with behaving proactively by goal setting or structuring their environment appropriately to achieve in their learning. Approximately $12 \%$ and $6 \%$ appeared to belong to this class, depicting this profile of self-regulated learning in study 1 and study 2 respectively.

We term individuals belonging to both class 2 and 3, which profiles forethought- and performance/reflection-endorsing self-regulators respectively, as being disorganized in the manner that they invoke skills and strategies associated with self-regulated learning. These learners would appear to need assistance in connecting different, less endorsed strategies and skills of self-regulated learning as being equally instrumental to them in achieving in their learning. Forethought- and performance/reflection-endorsing self-regulators, as disorganized selfregulators, may simply view that their current self-regulated learning strategies and skills are either the only or perhaps the best mechanisms to achieve in their learning. These individuals would appear to be more amenable to intervention on their behalf because these learners already 
endorse some self-regulated learning skills and strategies as compared to non- or minimal selfregulators as depicted by class 1 .

In the second study, we additionally examined the association of self-regulated learning profile membership as exhibited by latent class analyses with GPA. Our results indicated statistically significant differences in academic achievement (e.g., GPA) according to the class or profile of self-regulated learning that an individual belonged to. Super and competent self-regulators (e.g., classes 4 and 5 respectively) had the highest GPAs and were not significantly different from each other in GPA. Our results indicate that while being or becoming a super self-regulator would appear to be preferable, competent self-regulators do just as well in terms of academic achievement by most likely navigating and figuring out their learning environment enough to achieve well. Non-self-regulators (or minimal self-regulators) along with forethought- and performance/reflection-endorsing self-regulators had the lowest GPAs and were not significantly different from each other in GPA. These results would indicate that minimal and disorganized profiles of self-regulated learning are both associated with similar, poorer academic outcomes (e.g., lower GPAs). Our results appear to indicate that disorganization in self-regulated learning strategies and skills is as non-advantageous to a learner as non-existent or minimal selfregulation.

We suggest that these profiles in self-regulated learning may be viewed as contributing to the development of theory by elucidating how exactly individuals are and are not self-regulated in their learning in view of the development of self-regulated learning. The results of the current study suggest that individuals may not only be different in the quantitative level or amount in which they are self-regulated in their learning but also as to the form that this difference takes. For instance, in examining total self-regulated learning scale scores, our results indicated no significant differences between individuals belonging to classes 2 (e.g., forethought-endorsing self-regulators) and 3 (e.g., performance/reflection-endorsing self-regulators). Thus, in examining aggregate self-regulated learning scores, we would not be able to distinguish individuals belonging to classes 2 and 3 nor be able to term these individuals as disorganized in their selfregulation as we would not observe the form of these differences by specific skill or strategy. It is only through examining the subscale scores for the individual skills and strategies of selfregulated learning (e.g., goal setting, task strategies, etc.) that we would be able to discern the form of these differences in self-regulated learning for these disorganized self-regulators.

While the results of the current study provide insight into how learners are and are not selfregulated in view of theory, there are certain limitations that accompany the interpretation of our findings. For the samples in both study 1 and study 2, the mean values for GPA may be considered high as compared to the population of college students at large. Students with higher GPAs may enroll in online courses at higher rates as a result of having higher degrees of selfefficacy, the belief that they can achieve in courses delivered at a distance or in other nontraditional formats. Due to this possible bias in our samples, we suggest that future research be performed that represents a better range or diversity of learners in terms of academic achievement. Additionally, the results of the current study may be exclusive in their application to 
online learners as learners in other learning environments may reveal different profiles of selfregulated learning according to discipline or domain.

Future research should consider replicating the results of the current study with respect to learners in other domains and learning environments. The context of learning has been noted as influencing the way students approach their learning (Severiens, Ten Dam, \& Wolters, 2001). As such, Schunk (2001) has noted that self-regulated learning behaviors are "highly context dependent" (p. 125), thus future research will be required to replicate the results of the current study across several domains in order to cross-validate our findings for these five, distinct selfregulated learning profiles. Additionally, future research should also examine other cognitive factors, such as epistemological beliefs (e.g. Barnard, Lan, Crooks, \& Paton, 2008; Pintrich \& Zusho, 2002), which may be associated with the profile of self-regulated learning to which an individual belongs. We suggest that individuals with more sophisticated or constructivistoriented epistemological beliefs would more likely be profiled as super or competent selfregulators. For instance, in another study of online learners, Barnard, Lan, Crooks, and Paton (2008) found a statistically significant and highly positive relationship between epistemological beliefs and self-regulated learning skills. 


\section{References}

Ally, M. (2004). Foundations of educational theory for online learning. In T. Anderson (Ed.), The theory and practice of online learning (pp. 15-44). Edmonton, CA: Athabasca University Press.

Bandura, A. (1997). Self-efficacy: The exercise of control. New York: Freeman.

Bandura, A. (1986). Social foundations of thought and action: A social cognitive theory. Englewood Cliffs, NJ: Prentice-Hall.

Barnard, L., Lan, W. Y., Crooks, S. M., \& Paton, V. O. (2008). The relationship of epistemological beliefs with self-regulatory skills in the online course environment. Journal of Online and Learning Teaching, 4(3), 261-266.

Barnard, L., Lan, W. Y., To, Y. M., Paton, V. O., \& Lai, S. L. (2009). Measuring self-regulation in online and blended learning environments. The Internet and Higher Education, 12, 16.

Barnard, L., Paton, V.O., \& Lan, W. Y. (2008). Online self-regulatory learning behaviors as a mediator in the relationship between online course perceptions with achievement. International Review of Research in Open and Distance Learning, 9(2), 1-11.

Barnard-Brak, L., Paton, V.O., \& Lan, W. Y. (in press). Self-regulation across time of firstgeneration online learners. Journal of Association of Learning and Technology.

Boekaerts, M., \& Cascallar, E. (2006). How far have we moved toward the integration of theory and practice in self-regulation? Educational Psychology Review, 18, 199-210.

Cohen, J. (1988). Statistical power analysis for the behavioral sciences $\left(2^{\text {nd }}\right.$ ed.). Hillsdale, NJ: Lawrence Erlbaum \& Associates.

D’Unger, A., Land, K., McCall, P., \& Nagin, D. (1998). How many latent classes of delinquent/criminal careers? Results from mixed Poisson regression analyses of the London, Philadelphia, and Racine cohort studies. American Journal of Sociology, 103, 1593-1630.

Enders, C. K., \& Bandalos, D. L. (2001). The relative performance of Full Information Maximum Likelihood estimation for missing data in structural equation models. Structural Equation Modeling, 8(3), 430-457.

Field, A. (2005). Discovering statistics using SPSS (2nd ed.). Thousand Oaks, CA: Sage. 
Greene, J. A., \& Azevedo, R. (2007). A theoretical review of Winne and Hadwin's model of selfregulated learning: New perspectives and directions. Review of Educational Research, 77(3), 334-372.

Kirk, R. E. (1995). Experimental design: Procedures for the behavioral sciences (3rd ed.). Brooks/Cole Publishing Co.

Kramarae, C. (2001). The third shift: Women learning online. Washington, D.C.: American Association of University Women Educational Foundation Press.

Lo, Y., Mendell, N., \& Rubin, D. B. (2001). Testing the number of components in a normal mixture, Biometrika, 88, 767-778.

Martin, J. (2004). Self-regulated learning, social cognitive theory, and agency. Educational Psychologist, 39(3), 135-145.

Muthén, B. O. (2002). Beyond SEM: General latent variable modeling. Behaviormetrika, 29(1), 81-117.

Muthén, B. O. (2000). Methodological issues in random coefficient growth modeling using a latent variable framework: Applications to the development of heavy drinking. In J. Rose, L. Chassin, C. Presson \& J. Sherman (Eds.), Multivariate applications in substance use research (pp. 113-140). Hillsdale, NJ: Erlbaum.

Muthén, L. K., \& Muthén, B. O. (2008). MPlus user's guide. Los Angeles, CA: Muthén \& Muthén.

Muthén, L. K., \& Muthén, B. O. (2001). MPlus user’s guide ( $2^{\text {nd }}$ ed.). Los Angeles, CA: Muthén $\&$ Muthén.

Muthén, B. O., \& Muthén, L. K. (2000). Integrating person-centered and variable-centered analyses: Growth mixture modeling with latent trajectory classes. Alcohol Clinical \& Experimental Research, 24, 882-891.

Nagin, D. S. (2005). Group-based modeling of development. Cambridge, MA: Harvard University Press.

Nunnally, J. C. (1978). Psychometric theory (2 ${ }^{\text {nd }}$ ed.). New York: McGraw-Hill.

Pintrich, P. R. (2000). The role of goal orientation in self-regulated learning. In M. Boekaerts, P. R. Pintrich \& M. Zeidner (Eds.), Handbook of self-regulation (pp. 451-502). San Diego, CA: Academic. 
Pintrich, P. R., \& Zusho, A. (2002). The development of academic self-regulation: The role of cognitive and motivational factors. In A. Wigfield \& J. S. Eccles (Eds.), Development of achievement motivation (pp. 249-284). San Diego, CA: Academic.

Raftery, A. E. (1995). Bayesian model selection in social research. Sociologial Methodology, 25, 111-163.

Schunk, D. H. (2005). Self-regulated learning: The educational legacy of Paul R. Pintrich. Educational Psychologist, 40(2), 85-94.

Schunk, D. H. (2001). Social cognitive theory and self-regulated learning. In B.J. Zimmerman \& D.H. Schunk, (Eds). Self-regulated learning and academic achievement ( $2^{\text {nd }}$ edition). Mahwah, NJ: Lawrence Erlbaum.

Schunk, D.H., \& Zimmerman, B.J. (1998). Self-regulated learning: From teaching to selfreflective practice. New York: Guilford Press.

Severiens, S., Ten Dam, G., \& Wolters, B. V. H. (2001). Stability of processing and regulation strategies: Two longitudinal studies on student learning. Higher Education, 42(4), 437453.

Widaman, K. F. (2006). Missing data: What to do with or without them. Monographs of the Society for Research in Child Development, 71(3), 42-64.

Winne, P. H., \& Jamieson-Noel, D. (2002). Exploring students' calibration of self-reports about study tactics and achievement. Contemporary Educational Psychology, 27, 551-572.

Woolfolk, A. E., Winne, P. H., \& Perry, N. E. (2000). Educational psychology. Scaborough, Ontario, Canada: Allyn and Bacon.

Zimmerman, B. J. (1998). Academic studying and the development of personal skill: A selfregulatory perspective. Educational Psychologist, 33, 73-86.

Zimmerman, B. J. (1994). Dimensions of academic self-regulation: A conceptual framework for education. In D. H. Schunk \& B. J. Zimmerman (Eds.), Self-regulation of learning and performance (pp. 3-21). Hillsdale, NJ: Lawrence Erlbaum.

Zimmerman, B.J. \& Schunk, D. H. (2001). Self-regulated learning and academic achievement: Theoretical perspectives ( $2^{\text {nd }}$ ed.). Mahwah, NJ: Lawrence Erlbaum Associates. 


\section{Appendix}

\begin{tabular}{ll}
\hline Item & Subscale
\end{tabular}

1. I set standards for my assignments in online courses.

Goal Setting

2. I set short-term (daily or weekly) goals as well as long-term goals (monthly or for the semester).

3. I keep a high standard for my learning in my online courses.

4. I set goals to help me manage studying time for my online courses.

5. I don't compromise the quality of my work because it is online.

6. I choose the location where I study to avoid too much distraction. Environment Structuring

7. I find a comfortable place to study.

8. I know where I can study most efficiently for online courses.

9. I choose a time with few distractions for studying for my online courses.

10. I try to take more thorough notes for my online courses because notes are even more important Task Strategies for learning online than in a regular classroom.

11. I read aloud instructional materials posted online to fight against distractions.

12. I prepare my questions before joining in the chat room and discussion.

13. I work extra problems in my online courses in addition to the assigned ones to master the course content.

14. I allocate extra studying time for my online courses because I know it is time-demanding. Time

15. I try to schedule the same time every day or every week to study for my online courses, and I Management observe the schedule.

16. Although we don't have to attend daily classes, I still try to distribute my studying time evenly across days.

17. I find someone who is knowledgeable in course content so that I can consult with him or her Help Seeking when I need help.

18. I share my problems with my classmates online so we know what we are struggling with and how to solve our problems.

19. If needed, I try to meet my classmates face-to-face.

20. I am persistent in getting help from the instructor through e-mail.

21. I summarize my learning in online courses to examine my understanding of what I have Self-Evaluation learned.

22. I ask myself a lot of questions about the course material when studying for an online course.

23. I communicate with my classmates to find out how I am doing in my online classes.

24. I communicate with my classmates to find out what I am learning that is different from what they are learning. 


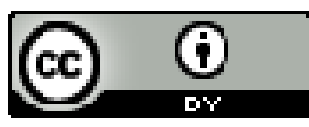

Athabasca

University 